Research Article

\title{
Experimental Verification of Applying Active Control Method as Virtual Support for Relief Bridge
}

\author{
Ming-Hsiang Shih $\mathbb{I D}^{1}$ and Wen-Pei Sung $\mathbb{D}^{2}$ \\ ${ }^{1}$ Department of Civil Engineering, National Chi-Nan University, Pu-Li, Nan-Tou 545, Taiwan \\ ${ }^{2}$ Department of Landscape Architecture, Integrated Research Center for Green Living Technologies, \\ National Chin-Yi University of Technology, Taichung 41170, Taiwan \\ Correspondence should be addressed to Wen-Pei Sung; wps@ncut.edu.tw
}

Received 11 March 2019; Accepted 19 May 2019; Published 19 June 2019

Academic Editor: Daniele Baraldi

Copyright (c) 2019 Ming-Hsiang Shih and Wen-Pei Sung. This is an open access article distributed under the Creative Commons Attribution License, which permits unrestricted use, distribution, and reproduction in any medium, provided the original work is properly cited.

\begin{abstract}
When natural disasters cause bridges to collapse, the delivery of rescue equipment and supplies to remote disaster areas is impeded and disaster relief efforts are thus delayed. In this study, to enhance and improve light bridges for disaster relief, a neutral equilibrium mechanism (NEM) is proposed to adjust the internal force of the bridge and reduce the deformation of the bridge. The NEM is installed at the center of a bridge to form a virtual bridge pier. A prototype of the NEM, composed of a pair of prestressed steel tendons, two pairs of anchor seats, a rotation cantilever arm mechanism, and a pair of radio-controlled (RC) servos, is proposed to test and verify the control effect of a bridge with the NEM. Test and analysis results show the following: (1) The rotation angle of the cantilever arm can be rotated by the RC servo to appropriate angles to provide adequate upwards resultant force to balance the moving load. (2) The vertical displacement of the bridge can be controlled to close to zero by this proposed NEM. (3) The maximum vertical displacement at the midpoint of a bridge with the NEM control mechanism can be controlled to far below 1/400 of the span of the bridge required by the design criteria. (4) A bridge under the control of an NEM under a lowspeed moving load with various control gains achieves fine displacement reduction effects, but the displacement reduction effect for a high-speed moving load with low control gain decreases. Test results also show that the bearing capacity of an existing bridge with an NEM can be increased and the weight of the bridge can be reduced. The effective span of a bridge can be increased without increasing the depth of the cross section. The feasibility and practicality of applying this proposed NEM to form a virtual pier of a bridge have been verified in this study.
\end{abstract}

\section{Introduction}

The intensity of natural disasters such as earthquakes, mudslides, and slope land collapses has increased recently. When such disasters occur, rescue equipment and supplies must arrive in disaster areas in the shortest possible time to save lives. If a bridge is damaged, rescuers will not be able to reach the disaster area and disaster relief will be delayed. Therefore, lightweight bridges for disaster relief are very important components of the disaster relief system.

To enhance and improve lightweight bridges for disaster relief, many scholars and research teams [1-5] have focused on improving bridge performance and applied FRP material as the construction material of bridge [6-10]. Especially, a cooperative research project by the National Center for Research on Earthquake Engineering (NCREE) and National Taipei University of Technology (NTUT) [11] has developed a lightweight cable-stayed bridge using fiberreinforced plastic (FRP) materials. They have broken new ground in the field of assembly efficiency and bearing capacity for this newly designed bridge. However, the erection of the lightweight bridge is restricted by the available space at the site, support conditions, and other factors in the area of the damaged bridge. Thus, the currently available structural system of a bridge cannot be applied to all disaster scenes. Therefore, an application of structure control (variable structure control), known as the neutral equilibrium mechanism (NEM), is proposed to adjust the internal force 
of the bridge and reduce the deformation of the bridge so as to achieve three effects: enhancing the bearing capacity of an existing bridge, reducing the dead load of a bridge, and increasing the effective span of a newly constructed bridge or an existing bridge.

The NEM is a mechanism that produces a control force for a bridge that reduces the deformation of the bridge structure under a moving load by means of active control. In this method, a force mechanism is installed at the midpoint of the bridge. This reaction mechanism takes the prestressed steel tendons as the reaction point and changes the action force (control force) to the bridge as the moving load shifts. Then, the vertical displacement of the bridge at the installation position can be controlled to almost zero. This NEM can achieve control performance requirements, which only require small energy to overcome the additional torque generated by inertia, friction loss, and control errors. Actually, the NEM applies the active structural control method to reduce the dynamic and static deformation of a lightweight bridge. This study excluded common active control, which requires a large energy supply.

To improve the capability of a structure to withstand a dynamic load and ensure the safety of people and objects around the structure, structural design technology has been under continuous development for many years. Active control [12-15] was developed in response to this requirement. Various systems such as supplementary damping system (SDS) [16-18], the mass damping system (MDS) [19-25], and active mass damping system (AMDS) $[26,27]$ have been widely studied and applied in active structural control. These systems have been tested and their performance verified on long structures that are highly sensitive to external disturbances. The control force of AMDS is generated by the calculated control force, based on the structural acceleration, velocity, and displacement responses induced by the external excitation force. The key to the interior of these damping systems is a controller that enhances the system's vibration decay rate. These controllers may be highly complex and require an intricate design, depending on the different characteristics of the control system.

To overcome the highly complex design mechanism of active control, this study proposes a neutral equilibrium mechanism (NEM) consisting of a set of stable and unstable equilibrium components based on the concept of the neutral equilibrium mechanism [28]. This prototype of an NEM is composed of a pair of prestressed steel tendons, two pairs of anchor seats, a rotation cantilever arm mechanism, and a pair of radio-controlled (RC) servos based on the concept and characteristics of NEM, and it is installed at the midpoint of the bridge to produce an upward resultant control force, in essence forming a virtual pier. A moving load traveling at various speeds was applied to a reduced-scale bridge with an NEM to test and verify the dynamic balance action force produced by the RC servo to rotate the cantilever arm to the appropriate position based on detection of the load with vibration sensors. These test results were compared with the test results of the same test model without an NEM to demonstrate control of the vertical displacement of the bridge to almost zero. To investigate the influence of the control gains of the PID controller for this proposed NEM, dynamic tests of a bridge with an NEM under low-speed and high-speed moving loads with various control gains were conducted and the displacement reduction effects were compared.

\section{Concept of Applying a Neutral Equilibrium Mechanism as a Virtual Pier}

The strength of the materials and functionality are two important factors in bridge design. Especially, The allowable vertical displacement of FRP pedestrian bridge should be less than $L$ (span of bridge)/400 [29]. The fundamental frequency of FRP pedestrian bridge on vertical direction should be greater than $3 \mathrm{~Hz}$ and $5 \mathrm{~Hz}$ for AASHTO and USDA, respectively. The fundamental frequency of FRP pedestrian bridge on lateral direction should be greater than $1.3 \mathrm{~Hz}$ and $3 \mathrm{~Hz}$ for AASHTO and USDA, respectively $[29,30]$. The load characteristics of a moving load affect the vertical deflection of a bridge. The vertical displacement should be restricted to within the allowable design values for vertical displacement of the bridge. To raise the traffic service standards and the structural safety of a bridge, the bridge deck section should be increased and materials of suitable strength should be selected. In addition, the span of a bridge is also affected by the design parameters of a dead load, a live load, a seismic load, wind force, etc. To reduce construction costs, a support point, or bridge pier, must be set up at the midpoint of a bridge to reduce the depth of the bridge section. However, the location of the pier is affected by geological conditions and other engineering factors. In this study, to control the vertical deflection of a bridge, the concept of the neutral equilibrium mechanism, or NEM, is applied to form a virtual pier for a bridge. This proposed NEM alters the upward active control force of NEM to bridge, the internal energy of NEM without increasing and decreasing. Then, the active control force of the control mechanism in the NEM can be changed according to variation in the vertical deflection of the bridge, which is affected by the moving load.

\subsection{Concept and Component Parts of the Neutral Equilibrium} Mechanism. The main concept of the neutral equilibrium mechanism is that an unstable control mechanism and a stable structure frame series are employed to achieve a neutral equilibrium system. This system does no damage to the structure caused by the unstable state of the structure, and it also produces arbitrary control force to the structure. Therefore, the prototype and control instruments of the NEM, illustrated in Figure 1, are proposed in this study.

This proposed prototype of an NEM to function as a virtual pier of a bridge is composed of a cantilever mechanism with two RC servos, two steel tendons, a microcontroller unit (MCU) [31], and anchor seats. The steel tendons with prestressed force provide the control force for the cantilever mechanism. The anchor seats fix the prestressed steel tendons in position. The MCU contains a CPU 


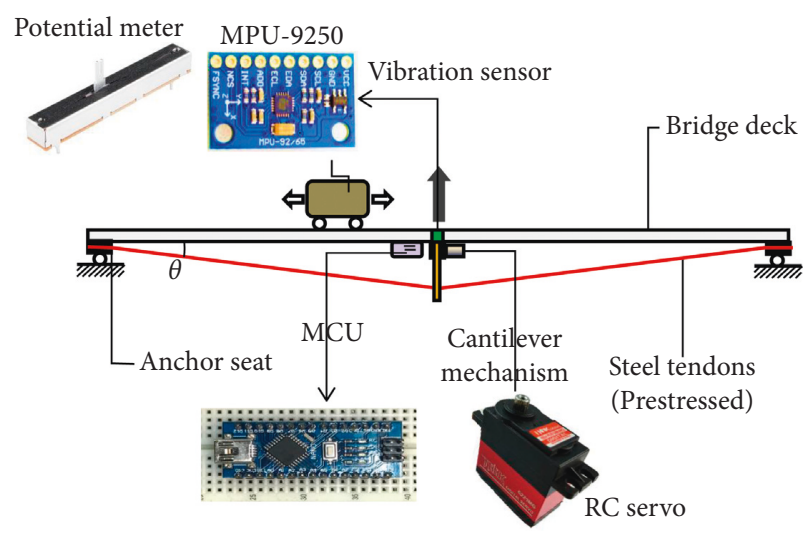

Figure 1: Prototype and control instruments of this proposed NEM as a virtual pier of a bridge.

(processor cores) along with memory and programmable input/output peripherals to detect the responses of the bridge at the installation position, induced by the vertical load from a moving load, and to provide control signal to the $\mathrm{RC}$ servo. The RC servo controls the rotation of the cantilever arm, which in turn controls the angle between the resultant force, provided by steel tendons on the lever arms, and the horizontal plan.

\subsection{Connections of the MCU and Instruments of the NEM.} The prototype of NEM is composed of two symmetrical cantilever mechanisms: two RC servos and a microcontroller unit (MCU) system. The MCU system includes an Arduino Nano, two acceleration sensors (MPU-9250), a potential meter, an SD module, and a $6 \mathrm{~V}$ power supply. The potential meter in this experimental set up is used to detect the variation in bridge displacement at the positions of the two symmetrical cantilever mechanisms. Sensors 1 and 2 of MPU-9250 are applied to measure the angle of lever arm and displacement meter, respectively. The MCU receives signals from the potential meter to change the rotation angle of the cantilever mechanisms so as to adjust the resultant force applied by the prestressed steel tendons of the NEM bridge and thereby cancel out the displacement of the bridge. The connections of the MCU and instruments of this proposed NEM are shown in Figure 1 and Table 1. The RC servo of the NEM can alter the rotation angle of the two symmetrical cantilever mechanisms. An RC servo is a main actuator for small-scale robotics that provides accurate rotation angles and sufficient torque with tiny energy supply. The RC servo is controlled by a pulse-width modulation (PWM) signal. The "width of duty cycle high" is applied to control the rotation angle of the RC servo via three wires: two wires for the DC power supply and one for the PWM signal. The angle of the actuator arm of the RC servo is moved by pulses sent over the control wire. A standard $90^{\circ} \mathrm{RC}$ servo is employed in this proposed NEM. A pulse of $1.0 \mathrm{~ms}$ duty-high sets it to $0^{\circ}$, and one of $2.0 \mathrm{~ms}$ duty-high, to $90^{\circ}$. In this research, a low-cost microcontroller, the Arduino Nano, is applied to serve as the controller of the whole system and to generate the PWM signal for the RC servo.
TABle 1: Connections of MCU and instruments.

\begin{tabular}{|c|c|c|c|}
\hline \multicolumn{2}{|c|}{ Vibration sensor-1 (2 pieces) } & \multicolumn{2}{|c|}{ Data recording } \\
\hline Arduino Nano & MPU-9250 & Arduino Nano & SD modulus \\
\hline GND & GND & GND & GND \\
\hline $3.3 \mathrm{~V}$ & $\mathrm{Vcc}$ & $5 \mathrm{~V}$ & Vcc \\
\hline A4 & SDA & D4 & CS \\
\hline A5 & SCL & D11 & MOSI \\
\hline GND (0x68) & $\mathrm{ADO}(\mathrm{CS})$ & D12 & MISO \\
\hline $3.3 \mathrm{~V}(0 \times 69)$ & & D13 & SCK \\
\hline \multicolumn{2}{|c|}{ Vibration sensor-2 } & \multicolumn{2}{|c|}{$\begin{array}{c}\text { Cantilever mechanism } \\
\text { ( } 2 \text { pieces })\end{array}$} \\
\hline Arduino Nano & Potential meter & Arduino Nano & RC servo \\
\hline GND & GND & GND & GND \\
\hline $5 \mathrm{~V}$ & $\mathrm{Vcc}$ & D9/D10 & Signal \\
\hline $\mathrm{A} 0$ & Signal & External $6 \mathrm{~V}$ & Vdd \\
\hline
\end{tabular}

2.3. Operation Mechanism. To describe the actual operating mechanism of the NEM in detail, the following graphics are specifically described. The bridge length is divided into four sections. The location labeled 2, in Figure 2, should have a pier for the bridge. This pier is replaced with the NEM to illustrate the operation of this mechanism. The operating mechanism of the NEM is described in five stages.

(i) Stage One. When the load is located at the beginning of the bridge, the microcontroller unit only detects the responses, induced by the weight of the bridge itself. The rotation angle of the cantilever arm is rotated to the nearly horizontal direction by the RC servo, as shown in Figure 2. The upwards resultant force is almost zero because there is no moving load on the bridge.

(ii) Stage Two. When the load moves onto the $1 / 4$ point of the bridge, the microcontroller unit detects the responses, induced by the moving load and the weight of the bridge itself. The rotation angle of the cantilever arm is transferred to the appropriate angle by the RC servo, as shown in Figure 3, to produce an appropriate upwards resultant force to balance the vertical load.

(iii) Stage Three. When the load is at the midpoint of the bridge, it is located directly above the virtual pier. The rotation angle of the cantilever arm is rotated to a larger angle by the $\mathrm{RC}$ servo to produce a larger upwards resultant force to balance the vertical load, as shown in Figure 4.

(iv) Stage Four. When the load moves to the $3 / 4$ point of the bridge, the rotation angle of the cantilever arm is rotated to an angle less than that of the third stage to balance the upwards resultant force and the vertical load, as shown in Figure 5.

(v) Stage Five. When the load moves to the end of the bridge, the situation is similar to that of the first stage. The microcontroller unit detects the responses, induced by the weight of the bridge itself again. The rotation angle of the cantilever arm is moved to the nearly horizontal direction by the RC servo. There is no moving load on the bridge; therefore, the upwards resultant force is almost zero, as shown in Figure 6. 


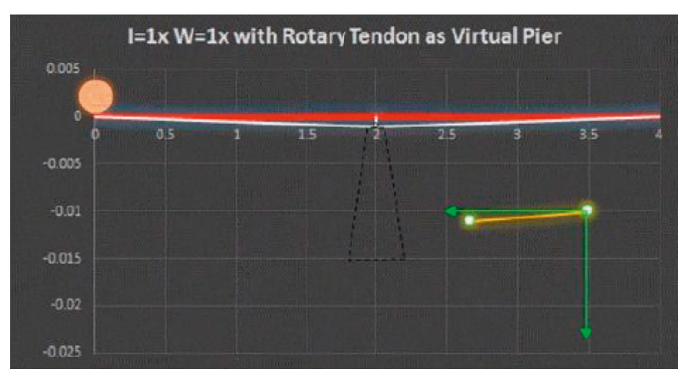

(a)

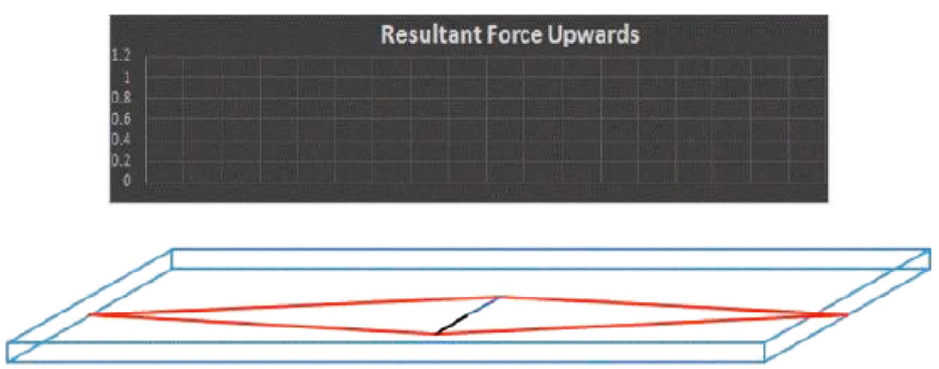

(b)

FIgURE 2: Rotation angle and upwards resultant force for the first stage of a bridge with the NEM.

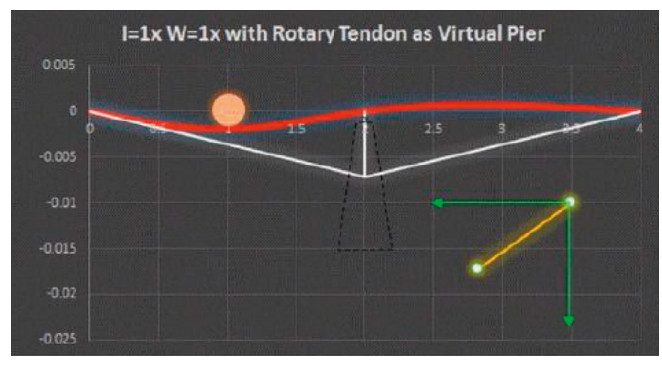

(a)

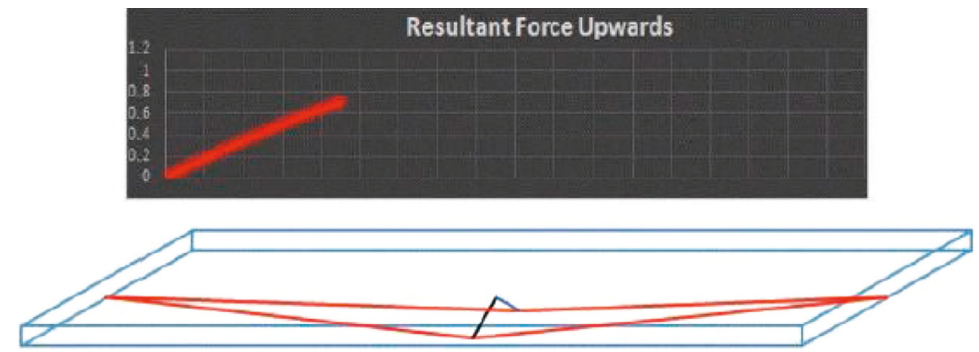

(b)

FIGURE 3: Rotation angle and upwards resultant force for the second stage of a bridge with the NEM.

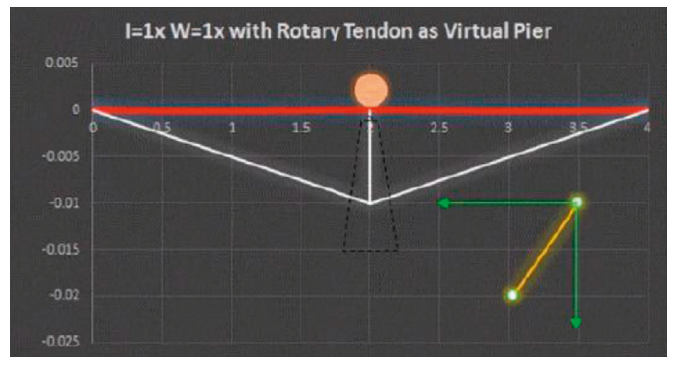

(a)

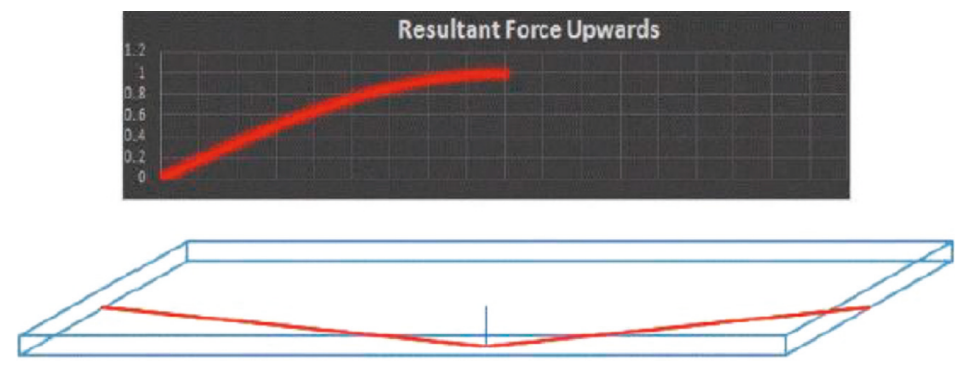

(b)

FIgURE 4: Rotation angle and upwards resultant force for the third stage of a bridge with the NEM.

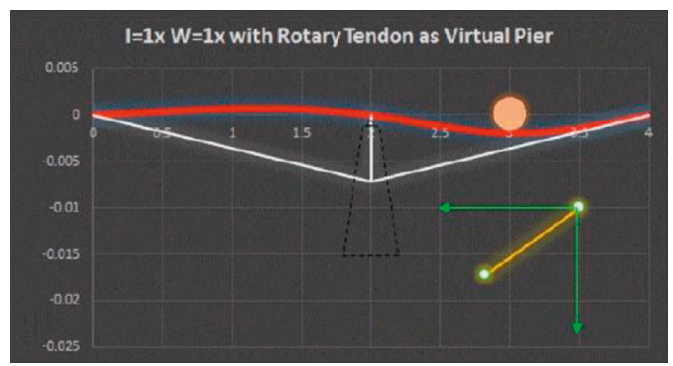

(a)

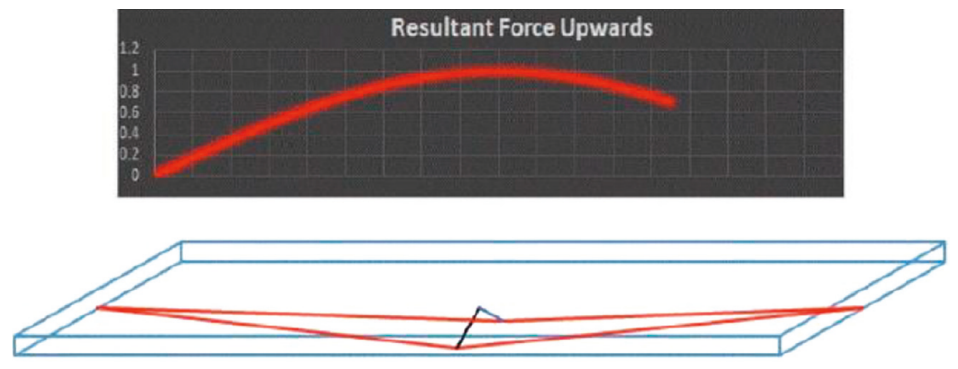

(b)

Figure 5: Rotation angle and upwards resultant force for the fourth stage of a bridge with the NEM. 


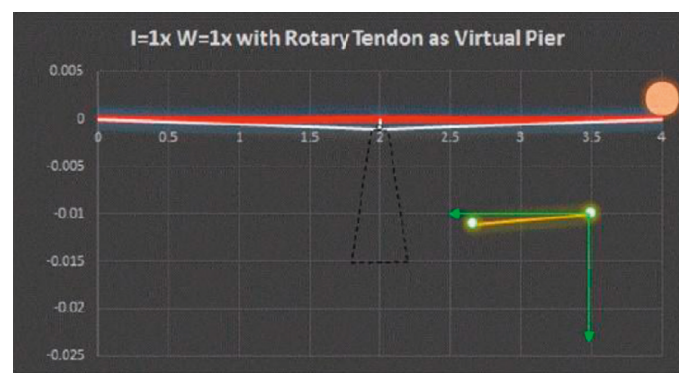

(a)

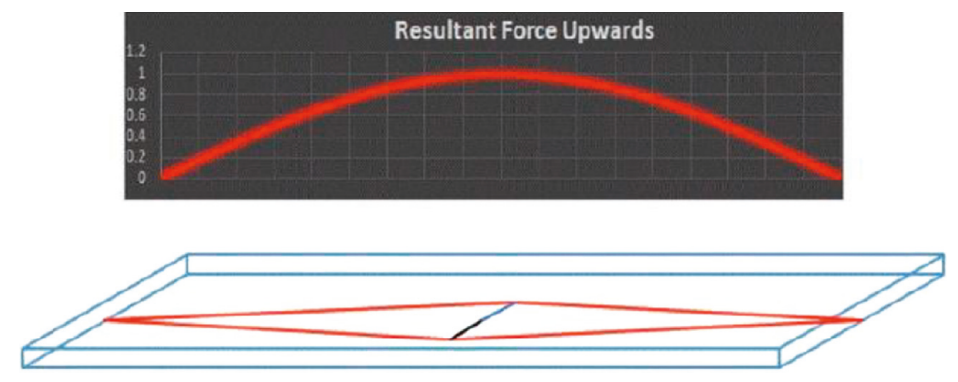

(b)

FIgURE 6: Rotation angle and upwards resultant force for the fifth stage of a bridge with the NEM.

2.4. Upwards Resultant Force of the Bridge with the NEM. In this study, the upwards resultant force $u$, also known as control force, provided by this proposed NEM is the vertical component of the resultant force $R$, acted on the cantilever arms, produced by the prestressed steel tendons, as shown in Figure 7. This force can form a virtual pier to provide the bridge an upward support force. A mathematical model of the concept of this proposed NEM can be described as follows.

Assuming the prestressed force of steel tendons as $T$, the span of the bridge as $L$ and the length of the cantilever arms as $l$, then the angle of the steel anchor line and tendon can be obtained as follows:

$$
\theta=\tan ^{-1}\left(\frac{2 l}{L}\right)
$$

Then, the resultant force $R$ can be obtained from $\theta$ as follows:

$$
\mathrm{R}=2 T \cdot \sin \theta \text {. }
$$

In the operating mode of this proposed NEM, vertical displacement signals detected by the potential meter are sent to the MCU, which orders the RC servo to rotate the cantilever arms to suitable angles to produce an upwards resultant force. The rotation angle of the cantilever arms varies from horizontal to vertical to the bridge deck, as shown in Figure 8.

The upwards resultant force $u$ can be adjusted through the rotation angles $\phi$ of the cantilever arms to change the direction of the force $R$ on the cantilever arms. $\phi$ is the angle between the cantilever arms and the bridge deck. The upwards resultant force $u$ is the size of the control force. The force direction is upward, which causes upward displacement to offset the downward displacement caused by the vehicle load. The horizontal component of the resultant force can be neutralized by the opposite directions of the two symmetric horizontal components of the cantilever arms. The control force $u$ can be obtained by $\phi$, as follows:

$$
u=2 T \cdot \sin \theta \cdot \sin \phi \text {. }
$$

\section{Control Law and Parameters of the NEM}

To deduce the control law and understand the forced behavior of a bridge with the NEM under a moving load of a vehicle, rigid body motion of a single degree of freedom (Figure 9) was investigated in this study. Then, a physical model was tested, and the theoretical model of this proposed model was investigated. The equation of motion for rigid body motion of a single degree of freedom is expressed as follows:

$$
m \cdot \ddot{x}+c \cdot \dot{x}+k \cdot x=p(t)-u(t)
$$

where $m$ represents the mass of the bridge; $c$ represents a damping coefficient; $k$ represents the stiffness of the spring; $x$ represents the vertical displacement of the bridge; $p(t)$ represents external force, relative to time; and $u(t)$ represents the control force of the NEM.

\subsection{Definitions of Control Force and Control Parameters.} The NEM can operate with a very small power supply and generate a powerful control force to counteract the effects of external forces on the bridge. To achieve the goal of automatic control to zero displacement at the installation position of the mechanism, the controller must continuously monitor variations in the vertical displacement of the bridge at the installation position of the mechanism. Therefore, the characteristics of the PID controller are applied in this study to calculate the target angle of the cantilever arm in the next stage, and then, the target angle is transmitted to the RC servos to complete the rotation angle of the cantilever arm.

Therefore, when the NEM is controlled, the linear control law is used in the calculation of the rotation angle in this study [32]. Defining the rotation angle is the linear combination of the displacement and velocity as one of the degrees of freedom reaction, shown as follows:

$$
\phi(t)=G_{P} \cdot x(t)+G_{I} \int_{o}^{t} x(t) d t+G_{D} \frac{d x(t)}{d t}
$$

where $G_{P}$ is the gain coefficient of displacement, proportional control gain; $G_{I}$ is the gain coefficient of the integral item, integral control gain, also called the adjustment coefficient; $G_{D}$ is the gain coefficient of velocity, differential control gain; $x(t)$ is the displacement function of the installation position of the NEM; and $t$ represents time.

Therefore, the rotation angle, produced by the NEM, can be expressed as follows:

$$
\phi(t)=G_{P} \cdot x(t)+G_{I} \int_{o}^{t} x(t) d t+G_{D} \frac{d x(t)}{d t} .
$$




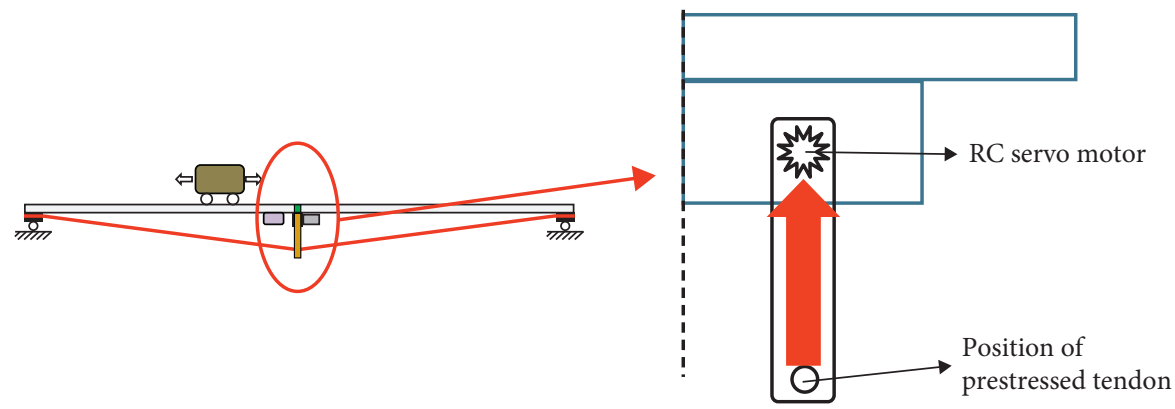

(a)

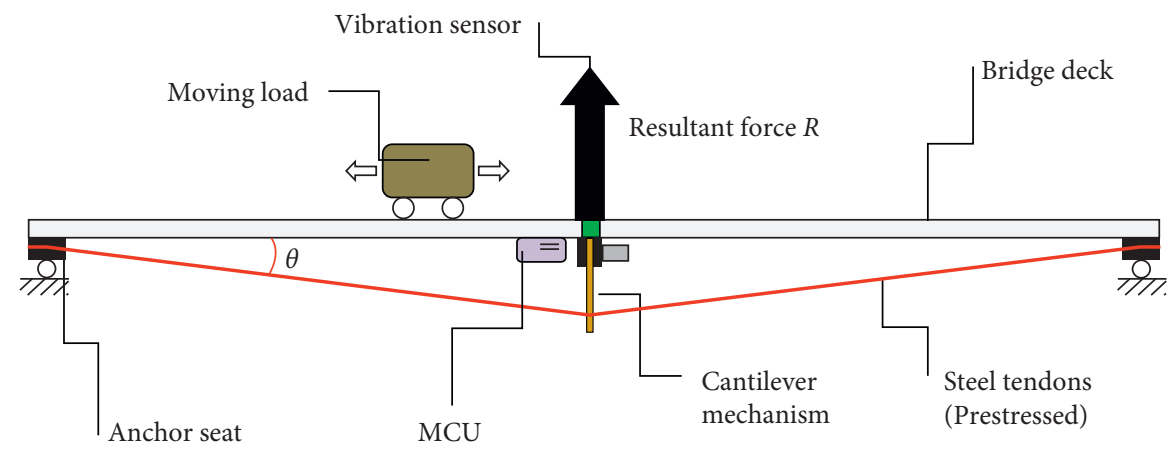

(b)

Figure 7: Side view of the NEM and resultant force $R$ (vertical line only). (a) Central sectional drawing of the NEM bridge. (b) Resultant force of the NEM.

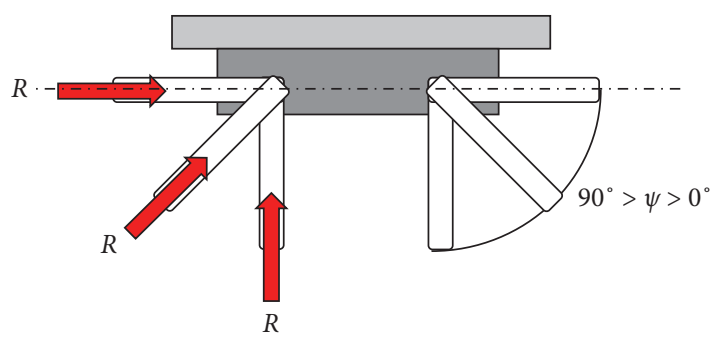

Figure 8: Front view of the NEM and angle variation [28].

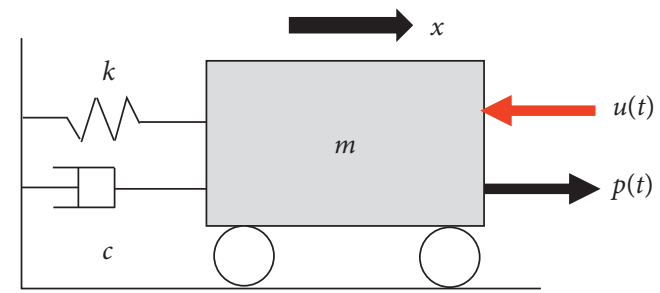

FIGURE 9: Diagram of a single degree of freedom for rigid motion of a bridge with the NEM.

In the discrete control system, equation (6) is equivalent to the following equation:

$$
\phi(t)=G_{P} \cdot \operatorname{Displ}+G_{I} \sum \mathrm{Displ}+G_{D} \cdot \text { Velocity. }
$$

3.2. Parameter Adjustment of the PID Controller. The control effect of the proportional control gain $\left(G_{P}\right)$ occurs when the upward control force increases or decreases with the downward displacement of the bridge at the installation position of this proposed mechanism. When the amount of vertical displacement at the installation position of this NEM is zero, the rotation angle, calculated by the first term of equation (5), is zero. It means that there is no control force. This result seems unreasonable. If a vehicle on the bridge is traveling at low speed, this control force cannot push the bridge back to its origin position. But, this component provides the effect of increasing the damping of the control system to improve the control stability of this NEM.

The effect of the integral gain coefficient $\left(G_{I}\right)$ indicates that the rate of increase of the angle is proportional to the downward displacement (assuming the direction of downward displacement is positive). The greater the downward displacement of the bridge is at the installation position of the NEM, the greater the rotation speed of the cantilever arm should be to quickly increase the upward control force. When the downward displacement at the installation position of the bridge is zero, the rotation angle of the cantilever arm remains unchanged to maintain the control force to offset the downward displacement of the bridge at the installation position of the NEM caused by the moving load. The control force created by this item is the main control force of the bridge with the NEM under static or slow-moving loads.

The effect of the differential gain coefficient $\left(G_{D}\right)$ is that the rotation angle of the cantilever arm increases with the speed of the downward motion and also provides the effect of increasing stability. 
To achieve the optimal control efficiency and control stability of the NEM, these three items need to be adjusted to achieve downward displacement control of the bridge. Problems with the settings of these three parameters may result in a poor control effect or stability problem. If these three control parameters can be adjusted carefully, the PID controller can provide a good control effect. In this study, the downward displacement of the bridge aimed to be zero, so the $G_{P}$ is set to zero. Since this study is aimed at relief bridges, the main goal of this NEM is to provide stability so as to reach the high stability of a relief bridge and meet the speed requirements of relief transportation facilities. Disaster relief vehicles are mainly heavy, so their traffic speeds are not high. In this study, the differential control gain $G_{\mathrm{D}}$ is set as $2.13^{\circ} / \mathrm{mm} / \mathrm{sec}$ to avoid unstable phenomenon. Then, to compare the downward displacement control effect and approach the speed of stability, the integral control gain $G_{I}$ is set to $8.53,17.07$, and $34.13^{\circ} / \mathrm{mm}$, respectively.

\section{Test Setup and Experimental Parameters}

To investigate the control effects and operation mode of NEM for bridge installed with the NEM, subjected to selfweight and service load, the reduced-scale bridge is designed to test and explore whether the operation of the NEM is consistent with the deduced operation mode and predicted control effects. The purpose of this experiment is to test and verify the feasibility, stability, and applicability of this proposed NEM.

4.1. Reduced-Scale Experimental Framework Design. The main body of this reduced-scale bridge is made by polypropylene plastic, PP Hard Plastic production; its length, width, and thickness are 1100, 120, and $15 \mathrm{~mm}$, respectively. The bridge support type is a simple support, and net span of bridge is $1020 \mathrm{~mm}$. Two Carbon Fiber lines with a tensile strength of $500 \mathrm{~N}$ are used to simulate the prestressed steel tendons of the bridge, hung by a steel block, with weight 196.25 N, provides a tensile prestressed force of $98.125 \mathrm{~N}$ of each Carbon Fiber line. The midpoint of the bridge is installed with NEM, contains two RC servos provided with the maximum torque $200 \mathrm{~N} \cdot \mathrm{cm}$, and cooperates with cantilever arm, with length $70 \mathrm{~mm}$. The request materials and specifications of this reduced-scale bridge test are listed in Table 2. The experimental framework of the overall reduced-scale bridge is shown in Figure 10.

The sensor part of this experiment is as follows: (1) displacement meter is set up at the midpoint of the bridge model to measure the displacement responses of the bridge; (2) microcontroller unit, MCU, is applied to measure the speed responses of bridge, calculated by the detected displacements and time interval of the sensor data of MCU. The displacement meter, of variable resistance, used in this research, is the resistive-type apparatus, set up at the midpoint of bridge. The displacement responses, generated by the self-weight of the bridge and moving load, promote the brushes to change the voltage size of the output and then calculate the displacement responses by the voltage change. The controller part uses an
Arduino Nano V3 microcomputer controller to take control of the operation of the entire NEM, including calculation, linking, and the transmission data to RC servos and displacement meters. The operating principle is to receive the displacement change of the midpoint of the bridge from the displacement meter and calculate its instantaneous velocity. Then, the required control force is calculated to predict the rotation angle (equation (7)) of RC servos to turn the RC servo.

4.2. Test Parameters. The purpose of this study is to verify the practicability and feasibility of this proposed NEM installed in bridge. The reduced-scale FRP bridge with NEM under dynamic moving load is investigated with the dynamic responses of bridge. The vertical displacement curves and mechanical behaviors of bridge without NEM and with NEM under various control parameters of PID controller are investigated whether the vertical displacement of bridge with NEM meet the requirements of the specification of FRP bridge $[27,28]$. In this study, the main power of RC servo, used in the remote control model with very little output power, is applied to explore the displacement reaction of bridge with NEM with various control gain under the action of low-speed and high-speed moving load to compare its deformation control effect. The test parameters of this experiment are listed in Table 3.

\section{Experimental Results and Discussion}

5.1. Test Results of Dynamic Tests with Low Speed. To test and verify the operation mechanism and control effects of the NEM, the dead load of the pulley block was $18.97 \mathrm{~N}$ and the speed across the bridge was $6.38 \mathrm{~cm} / \mathrm{sec}$ to explore the bridge deformation and the rotation angle of the RC servo changes. The test results are shown in Figure 11 and discussed according to the five stages described in Section 2.2.

(1) Stage One. The cantilever arm of the control mechanism maintains a horizontal orientation, and the vertical displacement of this test bridge is zero.

(2) Stage Two. When the pulley block is located at the $1 / 4$ point of the bridge, the vertical displacement of the bridge without the NEM is $4.0 \mathrm{~mm}$. With the NEM installed, however, the rotation angle of the RC servo is $18^{\circ}$ and the vertical displacement is only $0.13 \mathrm{~mm}$.

(3) Stage Three. When the pulley block is at the midpoint of the bridge, the vertical displacement of the bridge without the NEM is $4.95 \mathrm{~mm}$. With the NEM installed, however, the rotation angle of the servo increases to $24^{\circ}$ and the vertical displacement is only $0.17 \mathrm{~mm}$.

(4) Stage Four. When the pulley block is located at the $3 / 4$ point of the bridge, the vertical displacement of the bridge without the NEM is $2.2 \mathrm{~mm}$. With the NEM installed, however, the rotation angle of the RC servo is $18^{\circ}$ and the vertical displacement is only $0.15 \mathrm{~mm}$.

(5) Stage Five. The bridge bears only the dead load of the bridge. The rotation angle of the cantilever arm returns to the horizontal direction and the vertical displacement is zero. 
TABLE 2: Materials and specification of reduced scale of this test.

\begin{tabular}{|c|c|c|c|}
\hline Category & Materials & Specification & Quantity \\
\hline \multirow{3}{*}{ Control mechanism } & RC servo & $\begin{array}{l}\text { Size of torque: } 250 \mathrm{~N} \cdot \mathrm{cm} \\
\text { Angle control accuracy of RC servo: } 1.2^{\circ}\end{array}$ & 2 \\
\hline & Cantilever arm & $\begin{array}{c}\text { Length between the connection of fixed steel tendon } \\
\text { and anchor point: } 50 \mathrm{~mm} \\
\text { Material: polylactic acid (PLA), manufactured by } 3 \mathrm{D} \\
\text { printing }\end{array}$ & 2 \\
\hline & Polyethylene line (PE) & Tensile strength: $250 \mathrm{~N}$ & 1 \\
\hline \multirow[t]{2}{*}{ Model of bridge } & Bridge deck & $\begin{array}{l}\text { Size: length }=1100 \mathrm{~mm} \text {, width }=120 \mathrm{~mm} \text {, } \\
\text { thickness }=15 \mathrm{~mm}, \text { moment of inertia of } \\
\text { area }=2 \times 10^{5}\left(\mathrm{~mm}^{4}\right) \\
\text { Material: polypropylene plastic sheet, polypropylene } \\
(\mathrm{PP}) \text {; Young's modulus is between } 1300 \text { and } 1800 \\
\quad\left(\mathrm{~N} / \mathrm{mm}^{2}\right)\end{array}$ & 1 \\
\hline & Anchor seat & $\begin{array}{c}\text { Size: length }=120 \mathrm{~mm} \text {, width }=30 \mathrm{~mm} \text {, } \\
\text { thickness }=20 \mathrm{~mm} \\
\text { Material: aluminum alloy metal block; Support type: } \\
\text { simple support }\end{array}$ & 2 \\
\hline Sensor & Displacement meter & Resistive type & 1 \\
\hline Controller & Microcontroller unit (MCU) & Arduino Nano V3 & 1 \\
\hline
\end{tabular}

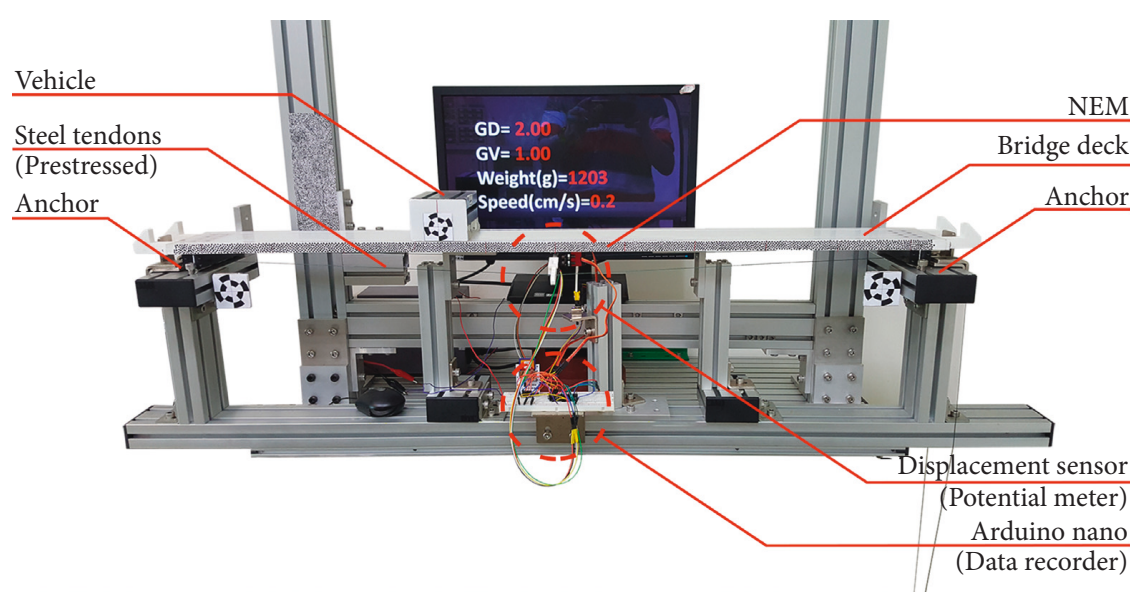

FIGURE 10: Experimental framework of overall reduced-scale bridge with NEM.

TABLE 3: Experimental parameter setting of this study.

\begin{tabular}{ll}
\hline Analysis parameter category & Parameter range \\
\hline & Self-weight: $18.97 \mathrm{~N}$; speed of vehicle: $6.38 \mathrm{~cm} / \mathrm{sec}$, speed of test vehicle is equivalent to $4.5 \mathrm{~km} / \mathrm{hr}$ \\
& (1) Without NEM control \\
Low-speed dynamic test & (2) Control gain of PID controller of NEM: \\
& (i) $G_{P}=0, G_{\mathrm{D}}=2.13^{\circ} / \mathrm{mm} / \mathrm{sec}, G_{I}=8.53^{\circ} / \mathrm{mm}$ \\
& (ii) $G_{P}=0, G_{\mathrm{D}}=2.13^{\circ} / \mathrm{mm} / \mathrm{sec}, G_{I}=17.07^{\circ} / \mathrm{mm}$ \\
& (iii) $G_{P}=0, G_{\mathrm{D}}=2.13^{\circ} / \mathrm{mm} / \mathrm{sec}, G_{I}=34.13^{\circ} / \mathrm{mm}$ \\
\hline
\end{tabular}

Self-weight: $18.97 \mathrm{~N}$, speed of vehicle: $22.7 \mathrm{~cm} / \mathrm{sec}$, speed of test vehicle is equivalent to $16 \mathrm{~km} / \mathrm{hr}$

(1) Without NEM control

High-speed dynamic test

(2) Control gain of PID controller of NEM:

(i) $G_{P}=0, G_{\mathrm{D}}=2.13^{\circ} / \mathrm{mm} / \mathrm{sec}, G_{I}=8.53^{\circ} / \mathrm{mm}$

(ii) $G_{P}=0, G_{\mathrm{D}}=2.13^{\circ} / \mathrm{mm} / \mathrm{sec}, G_{I}=17.07^{\circ} / \mathrm{mm}$

(iii) $G_{P}=0, G_{\mathrm{D}}=2.13^{\circ} / \mathrm{mm} / \mathrm{sec}, G_{I}=34.13^{\circ} / \mathrm{mm}$

Figure 11 shows that the maximum displacement of the time history of displacement variation at the midpoint of the bridge with the NEM control mechanism is less than $1 / 6000$ of the span of the bridge. This displacement conforms to bridge design guidelines. Furthermore, the time history of displacement variation of the bridge under NEM control shows that the vertical displacement of the bridge under NEM control is much smaller than that of the uncontrolled condition. The rotation angle of the cantilever arm of the NEM increases as the pulley block approaches the midpoint 


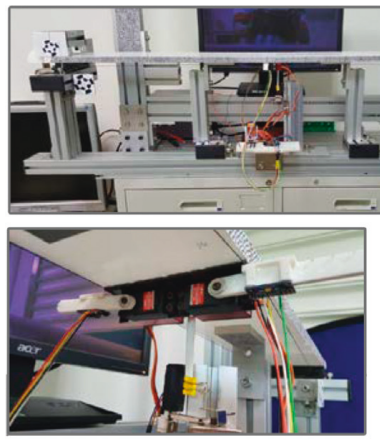

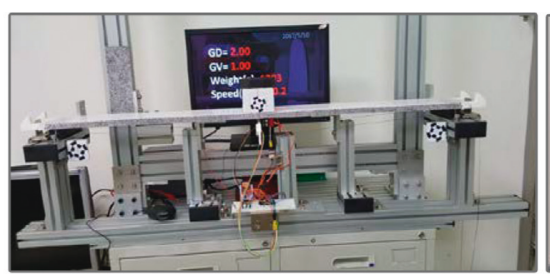

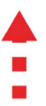

Moving load speed $=6.38 \mathrm{~cm} / \mathrm{sec}$

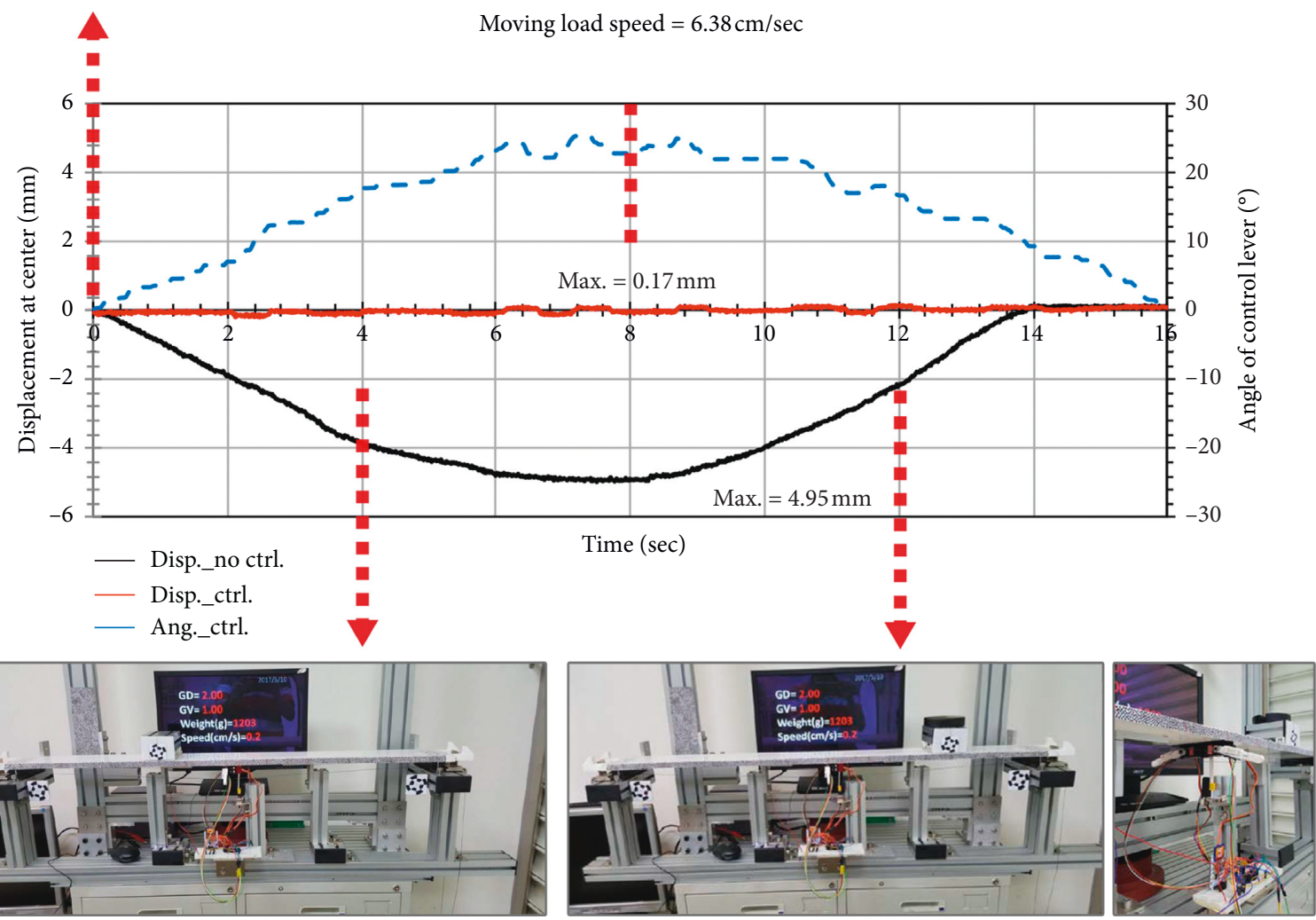

FIGURE 11: Comparison of the displacement control effects of a bridge without control and with NEM control and rotation angle variations of the bridge with NEM control at the midpoint of the bridge.

of the bridge to produce a larger upward lift force to balance the action force of the pulley block. Test results revealed that this proposed NEM can increase the effective span of the bridge and reduce bridge deformation without increasing the cross section of the bridge.

5.2. Control Effects of Dynamic Tests with Low and High Speeds with Various Gain Coefficients. Figures 12 and 13 display the time history of displacement responses at the midpoint of the bridge under low-speed and high-speed moving loads. These figures show the displacement responses at the midpoint of the bridge without control and under control of differential control gain of $2.13^{\circ} / \mathrm{mm} / \mathrm{sec}$ and integral control gains of $34.13,17.07$, and $8.53^{\circ} / \mathrm{mm}$ to compare the displacement reduction effects with various gain coefficients.

From Figure 12, it can be seen that the gain coefficients have an impact on the displacement control effect. The maximum displacement responses of the bridge decrease with increases in the gain coefficient under the control condition, without diverging. However, the displacement control effects of these three gain coefficients provide good control results, as shown in Figure 12. Displacement is reduced by $96.6 \%, 95.2 \%$, and $91.1 \%$, respectively. There is no visible difference between these three gain coefficients for bridge protection. But, this proposed NEM must have a minimum torque capacity proportional to the residual displacement. Therefore, a larger gain coefficient can be chosen without affecting the control of the stability of the bridge.

The displacement control effects for the bridge under a high-speed moving load (Figure 13) are slightly reduced. The gain coefficients greatly influence the displacement control effects. The reduction rate of the displacement control for the gain coefficient $G_{I}=34.13^{\circ} / \mathrm{mm}$ still reaches $91.0 \%$. But, it is only $74.5 \%$ for the gain coefficient $G_{I}=8.53^{\circ} / \mathrm{mm}$. As the 


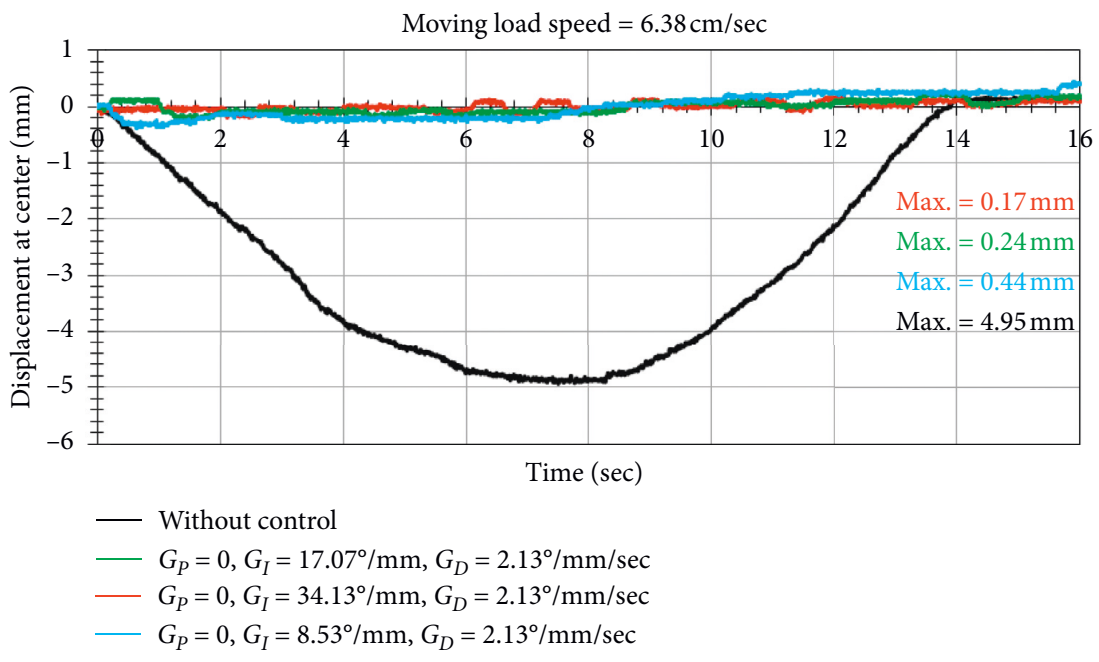

FIGURE 12: Comparison of the time histories of displacement responses for the bridge under a load of a low-speed vehicle without and with NEM control and various gain coefficients.

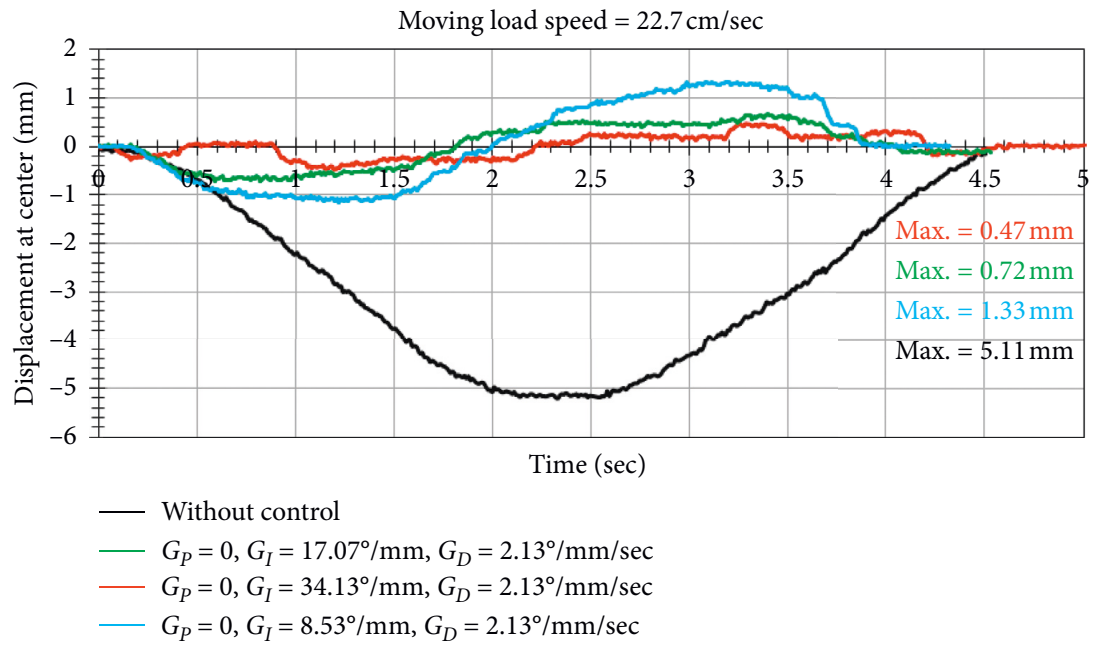

FIgURE 13: Comparison of the time histories of the displacement responses for the bridge under a load of a high-speed vehicle without and with NEM control and various gain coefficients.

gain coefficient increases, the maximum displacement response is reduced, and it increases as the moving load speed increases for the closed-loop control of the PID controller.

To obtain better displacement control effects, the moving speed should be limited. Actually, this limitation for disaster relief bridges has only a minor impact; after all, it is only a temporary support. But, the use of the bridge structure with NEM is greatly reduced for a bridge structure under a highspeed moving load. If the moving speed (location) of the moving load can be predicted under such conditions, the displacement control effect with open-loop control can be significantly improved. To extend the application of NEM method, multiple virtual bridge piers should be investigated in future studies.

\section{Conclusions}

The concept underlying this proposed device to form a virtual pier at the center of a bridge is that an unstable control mechanism connects a stable structure frame in series to constitute a neutral equilibrium mechanism (NEM). A prototype of the NEM, composed of a pair of prestressed steel tendons, an anchor seat, a rotation cantilever arm mechanism, and an RC servo, based on the concept and characteristics of the NEM, is proposed to test and verify the control effects of a bridge with an NEM installed at the midpoint of the bridge. Some conclusions can be summarized from a series of laboratory test results, as follows:

(1) The rotation angle of the cantilever arm, rotated by the RC servo, can be changed to appropriate angles to provide adequate upwards resultant force to balance the load based on the location of the moving load on the bridge.

(2) No matter the position of the moving load on the bridge, this proposed NEM can control the vertical displacement of the bridge to close to zero. 
(3) The time history of displacement variation at the midpoint of the bridge with the NEM control mechanism shows that the maximum vertical displacements are controlled to far below 1/400 of the span of the bridge required by the design criteria. The NEMinstalled bridge conforms to bridge design guidelines.

(4) No matter what the gain coefficients of the NEM are, displacement reductions of the bridge under control of the NEM with a low-speed moving load are greater than $90 \%$. There is no visible difference between these three gain coefficients for bridge protection.

(5) For the displacement control effects for the bridge under control of the NEM with a low-speed moving load, higher integral control gain leads to higher displacement control effects. But, the displacement reduction effect for a high-speed moving load with high integral control gain is decreased. Therefore, to obtain better displacement control effects, the moving speed should be limited.

This study confirms that the bearing capacity of an existing bridge with an NEM can be increased and the dead load of a bridge can be reduced. The effective span of the bridge can be increased without increasing the depth of the cross section. Test and analysis results verify the practicality of applying this proposed NEM to form a virtual pier of a bridge. Nevertheless, a simple device RC motor with slow reaction and low control accuracy is adopted as the actuator in this study to cause time lag and reduce the vertical displacement control effect of NEM. Therefore, the control methods of open-loop and closed-loop controls of the PID controller for this proposed NEM should be further investigated to examine the feasibility and practicability of this proposed NEM.

\section{Data Availability}

The data used to support the findings of this study are included within the article.

\section{Conflicts of Interest}

The authors declare that there are no conflicts of interest regarding the publication of this paper.

\section{Acknowledgments}

This research was funded by the Ministry of Science and Technology, Taiwan through grant numbers MOST 1072119-M-260-002, MOST 107-2221-E-167-001, and MOST108-2119-M-260-002.

\section{References}

[1] E. M. Laursen, "An analysis if relief bridge scour," Journal of the Hydraulics Division, vol. 89, no. 3, pp. 93-118, 1963.

[2] A. D. Buncio, New Technology Behind Emergency Bridge Construction, https://www.viatechnik.com/other/new-technologybehind-emergency-bridge-construction/.
[3] G. Sedlacek, H. Trumpf, and U. Castrischer, "Development of a light-weight emergency bridge," Structural Engineering International, vol. 14, no. 4, pp. 282-287, 2004.

[4] R. G. Wight, M. A. Erki, C. T. Shyu, R. Tanovic, and P. J. Heffernan, "Development of FRP short-span deployable bridge-experimental results," Journal of Bridge Engineering, vol. 11, no. 4, pp. 489-498, 2006.

[5] M. J. Robinson and J. B. Kosmatka, "Development of a shortspan fiber-reinforced composite bridge for emergency response and military applications," Journal of Bridge Engineering, vol. 13, no. 4, pp. 388-397, 2008.

[6] B. Tang and W. Podolny, "A successful beginning for fiber reinforced polymer (FRP) composite materials in bridge applications," in Proceedings of the International Conference on Corrosion and Rehabilitation of Reinforced Concrete Structures, FHWA Proceedings, Orlando, FL, USA, 1998.

[7] P. Qiao, J. F. Davalos, and B. Brown, "A systematic analysis and design approach for single-span FRP deck/stringer bridges," Composites Part B: Engineering, vol. 31, no. 6-7, pp. 593-609, 2000.

[8] S. Luke, L. Canning, S. Collins et al., "The development of an advanced composite bridge decking system-project ASSET," Structural Engineering International, vol. 12, no. 2, pp. 76-79, 2002.

[9] T. Kumada, S. Yamada, E. Johansen, and R. Wilson, "Static and dynamic behavior of a pultruded FRP truss footbridge," in Proceeding of the Second Asia-Pacific Conference on FRP in Structures, pp. 355-361, Seoul Korea, 2009.

[10] L. J. Jia and Y. Jiang, "Applications of FRP material in bridge structures," Advanced Materials Research, vol. 798-799, pp. 249-252, 2013.

[11] Y. C. Sung, F. Y. Yeh, and K. C. Chang, "Design concept and verification of temporary rescue brdge using lightweight composite materials," International Journal of Bridge Engineering (IJBE), vol. 2017, pp. 151-170, 2017.

[12] N. R. Fisco and H. Adeli, "Smart structures: Part I-Active and semi-active control," Scientia Iranica, vol. 18, no. 3, pp. 275-284, 2011.

[13] L. L. Chung, R. C. Lin, T. T. Soong, and A. M. Reinhorn, "Experimental study of active control for MDOF seismic structures," Journal of Engineering Mechanics, vol. 115, no. 8, pp. 1609-1627, 1989.

[14] K. Liu, L.-X. Chen, and G.-P. Cai, "Active control of a nonlinear and hysteretic building structure with time delay," Structural Engineering and Mechanics, vol. 40, no. 3, pp. 431-451, 2011.

[15] X. Zeng, Z. Peng, L. Mo, and G. Y. Su, “Active control based on prediction of structural vibration feedback," in Proceedings of the 2014 Fifth International Conference on Intelligent Systems Design and Engineering Applications, Warsaw, Poland, 2014.

[16] https://www.rwdimedia.com/uploads/1/1/2/7/11270509/rwdi_ damping_systems.pdf.

[17] N. Isyumov, P. Case, A. Hasan et al., "Monitoring of tall buildings to assist the design of supplementary damping systems," in Proceedings of the Structures Congress 2010, Orlando, FL, USA, 2010.

[18] R. Vargas and M. Bruneau, "Effect of supplemental viscous damping on the seismic response of structural systems with metallic dampers," Journal of Structural Engineering, vol. 133, no. 10, pp. 1434-1444, 2007.

[19] A. C. Webster and R. Vaicaitis, "Application of tuned mass dampers to control vibrations of composite floor systems," Engineering Journal, vol. 29, pp. 116-124, 1992. 
[20] A. Andersson, R. Karoumi, and A. O'Connor, "Vibration mitigation of railway bridges using adaptive damping control," in Proceedings of the International IABSE Conference, Rotterdam, Netherlands, 2013.

[21] B.-W. Jo, G.-H. Tae, and D.-W. Lee, "Structural vibration of tuned mass damper-installed three-span steel box bridge," International Journal of Pressure Vessels and Piping, vol. 78, no. 10 , pp. $667-675,2001$.

[22] C. C. Lin, J. F. Wang, and B. L. Chen, "Train-induced vibration control of high-speed railway bridges equipped with multiple tuned mass dampers," Journal of Bridge Engineering, vol. 10, no. 4, pp. 398-414, 2005.

[23] J. Li, M. Su, and L. Fan, "Vibration control of railway bridges under high-speed trains using multiple tuned mass dampers," Journal of Bridge Engineering, vol. 10, no. 3, pp. 312-320, 2005.

[24] S. Nagarajaiah and E. Sonmez, "Structures with semiactive variable stiffness single/multiple tuned mass dampers," Journal of Structural Engineering, vol. 133, no. 1, pp. 67-77, 2007.

[25] P. Pawelko, "Modeling mass-damper-spring systems in portable machine tools for flange machining," Achieves of Mechanical Technology and Automation, vol. 34, no. 1, pp. 13-23, 2014.

[26] S. M. Kim, S. Wang, and M. J. Brennan, "Robust broadband vibration control of a flexible structure using an electrical dynamic absorber," Smart Materials and Structure, vol. 20, no. 9pp, p. 075002, 2011.

[27] F. Weber, "Optimal semi-active vibration absorber for harmonic excitation based on controlled semi-active damper," Smart Materials and Structure, vol. 23, no. 9, article 095033, 2014.

[28] M. H. Shih and W. P. Sung, "Developing a neutral equilibrium device as dynamic virtual piers for an emergency relief bridge," in Proceedings of the 13th International Conference on Computational Structures Technology, Barcelona, Spain, 2018.

[29] American Association of State Highway and Transportation Officials (AASHTO), Guide Specifications for Design of FRP Pedestrian Bridges, AASHTO, Washington, DC, USA, 1st edition, 2008.

[30] Department of Agriculture, Forest Service, Technology \& Development Program, A Guide to Fiber-Reinforced Polymer Trail Bridges, Department of Agriculture, Forest Service, Technology \& Development Program, Missoula, MT, USA, 2011.

[31] https://en.wikipedia.org/wiki/Microcontroller.

[32] T. T. Soong and B. F. Spencer Jr., "Active, semi-active and hybrid control of structures," in Proceedings of the 12th World Conference on Earthquake Engineering, pp. 2-5, Auckland, New Zealand, 2000. 


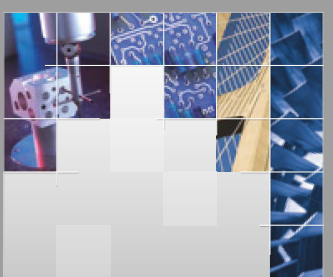

\section{Enfincering}
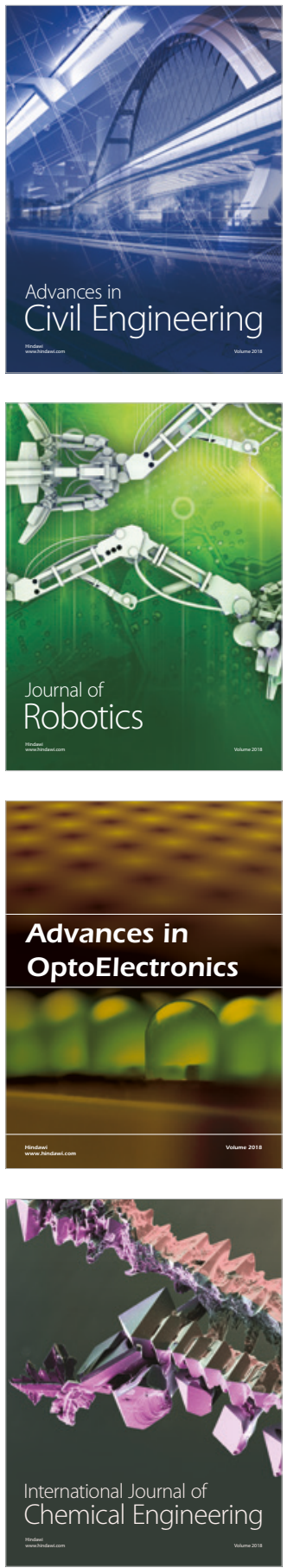

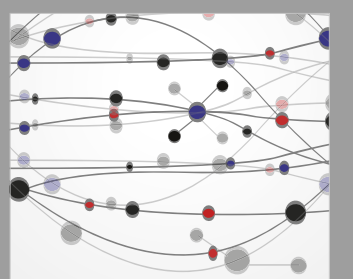

\section{Rotating \\ Machinery}

The Scientific World Journal

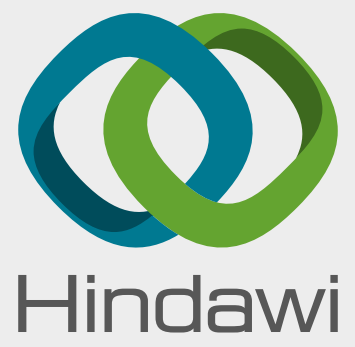

Submit your manuscripts at

www.hindawi.com
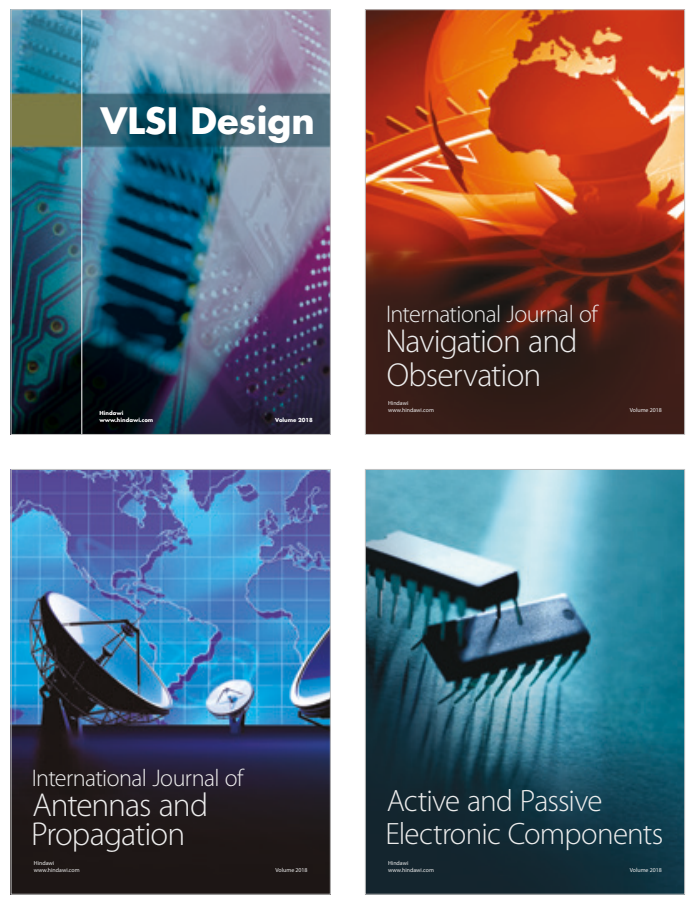
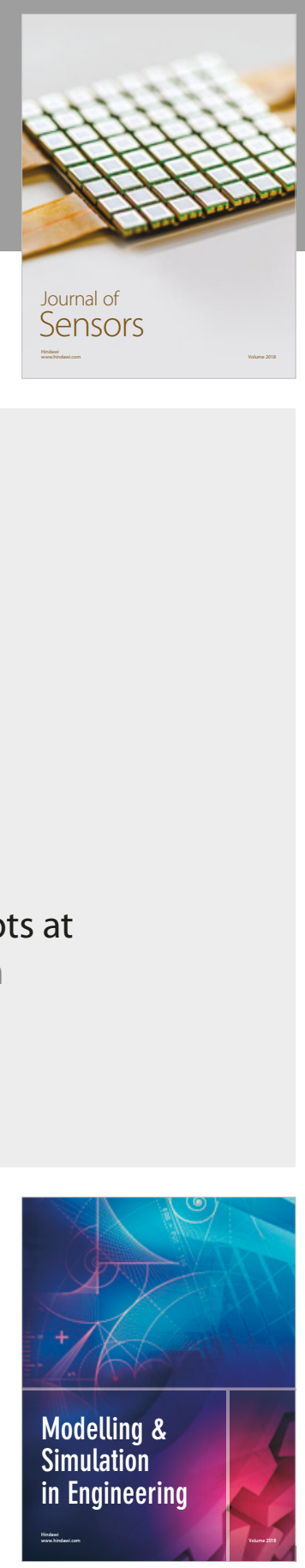

\section{Advances \\ Multimedia}
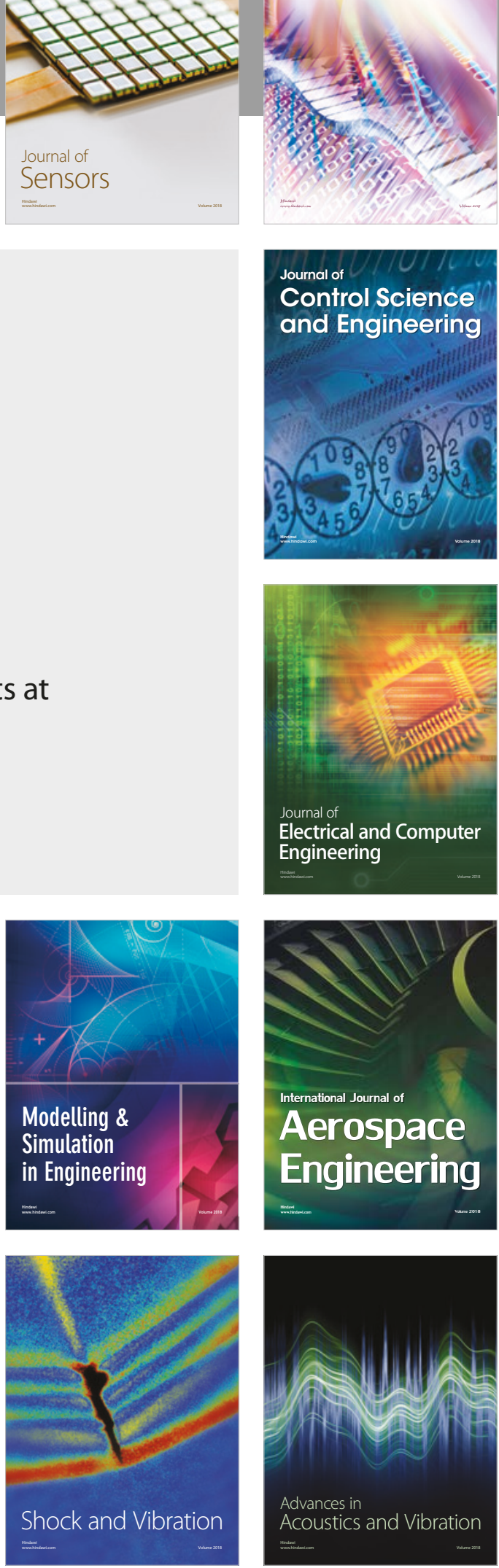